\title{
Purification and characterization of a novel ginsenoside Rc-hydrolyzing $\beta$-glucosidase from Armillaria mellea mycelia
}

\author{
Jitendra Upadhyaya ${ }^{1}$, Min-Sun Yoon ${ }^{2}$, Min-Ji Kim ${ }^{1}$, Nam-Soo Ryu ${ }^{2}$, Young-Eun Song ${ }^{3}$, Young-Hoi Kim ${ }^{1}$ \\ and Myung-Kon Kim ${ }^{1 *}$
}

\begin{abstract}
Ginsenosides are the principal compounds responsible for the pharmacological effects and health benefits of Panax ginseng root. Among protopanaxadiol (PPD)-type ginsenosides, minor ginsenosides such as ginsenoside (G)-F2, G-Rh2, compound (C)-Mc1, C-MC, C-O, C-Y, and C-K are known to be more pharmacologically active constituents than major ginsenosides such as G-Rb1, G-Rb2, G-Rc, and G-Rd. A novel ginsenoside Rc-hydrolyzing $\beta$-glucosidase (BG-1) from Armillaria mellea mycelia was purified as a single protein band with molecular weight of $121.5 \mathrm{kDa}$ on SDS-PAGE and a specific activity of $17.9 \mathrm{U} \mathrm{mg}^{-1}$ protein. BG-1 concurrently hydrolyzed $\mathrm{a}-(1 \rightarrow 6)$-arabinofuranosidic linkage at the C-20 site or outer $\beta$ - $(1 \rightarrow 2)$-glucosidic linkage at the $C-3$ site of G-Rc to produce G-Rd and C-Mc1, respectively. The enzyme also hydrolyzed outer and inner glucosidic linkages at the C-3 site of G-Rd to produce C-K via G-F2, and inner glucosidic linkage at the C-3 site of C-Mc1 to produce C-Mc. C-Mc was also slowly hydrolyzed a- $(1 \rightarrow 6)$-arabinofuranosidic linkage at the $\mathrm{C}-20$ site to produce $\mathrm{C}-\mathrm{K}$ with reaction time prolongation. Finally, the pathways for formation of C-Mc and C-K from G-Rc by BG-1 were G-Rc $\rightarrow$ C-Mc1 $\rightarrow$ C-Mc and G-Rc $\rightarrow$ G-Rd $\rightarrow$ G-F2 $\rightarrow$ C-K, respectively. The optimum reaction conditions for C-Mc and C-K formation from G-Rc by BG-1 were pH 4.0-4.5, temperature $45-60{ }^{\circ} \mathrm{C}$, and reaction time $72-96 \mathrm{~h}$. This is the first report of efficient production of minor ginsenosides, $\mathrm{C}-\mathrm{Mc}$ and $\mathrm{C}-\mathrm{K}$ from G-Rc by $\beta$-glucosidase purified from A. mellea mycelia.
\end{abstract}

Keywords: Armillaria mellea, $\beta$-Glucosidase, Enzymatic hydrolysis, Ginsenoside Rc, Minor ginsenosides

\section{Introduction}

Ginseng, root of Panax ginseng C. A. Meyer, has been used as a traditional folk medicine in East Asian countries such as Korea, Japan and China for thousands of years, and has to some extent been popularized in many western countries during recent decades. The major pharmacologically active constituents of ginseng are triterpenoid saponins called ginsenosides. They can be classified into two groups by the skeleton of their aglycones, dammarane-type and oleanane-type. The dammaranetype ginsenosides can also be classified into protopanaxadiol (PPD)-type and protopanaxatriol (PPT)-type (Attele

\footnotetext{
*Correspondence: kmyuko@jbnu.ac.kr

${ }^{1}$ Department of Food Science and Technology, Chonbuk National University, Jeonju 54896, Republic of Korea

Full list of author information is available at the end of the article
}

et al. 1999). Naturally occurring major PPD-type ginsenosides such as ginsenoside (G)-Rb1, G-Rb2, G-Rc, and G-Rd (Fig. 1) are hardly absorbed by the human intestinal tract (Hasegawa et al. 1996; Tawab et al. 2003). Conversely, minor ginsenosides such as G-Rg3, G-F2, G-Rh2, and compound (C)-O, C-Y, C-Mc1, C-Mc, and C-K, the hydrolyzed products obtained from major ginsenosides, are more readily absorbed into the bloodstream and function as active compounds (Tawab et al. 2003; Yang et al. 2015). The minor ginsenosides have been demonstrated to possess multiple pharmacological effects, such as anticarcinogenic (Park et al. 2005), immunomodulatory (Liu et al. 2014), anti-inflammatory (Park et al. 2012; Lee and Lau 2011), antiatherosclerotic (Park et al. 2005), antihypertensive (Christensen 2008), antigenotoxic (Lee et al. 1998), and antidiabetic properties ( $\mathrm{Li}$ et al. 2012). C-K is the major active metabolite of PPD-type ginsenosides 


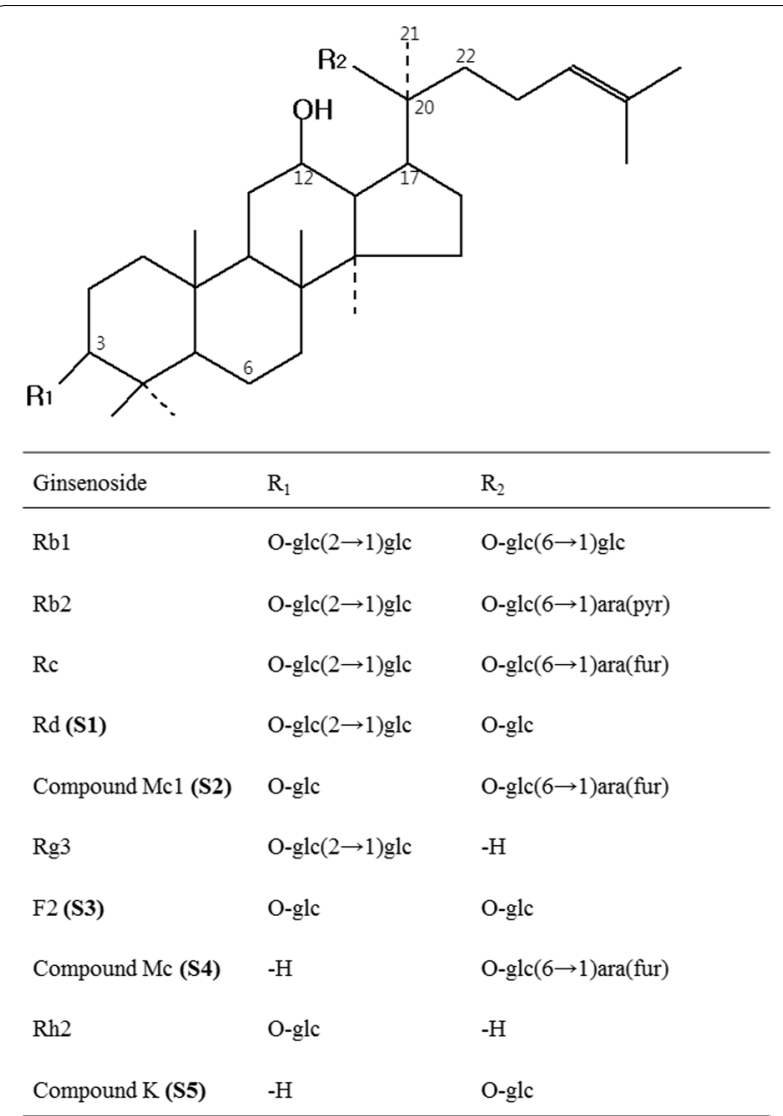

Fig. 1 Chemical structures of protopanaxadiol type ginsenosides. The ginsenosides represented are all (S)-type ginsenosides. glc, $\beta$-D-glucopyranosyl; ara (pyr), a-L-arabinopyranosyl; ara (fur), a-Larabinofuranosyl

produced by human intestinal bacteria (Karikura et al. 1991; Hasegawa et al. 1997).

Various methods have been studied to produce the more active minor ginsenosides from major ginsenosides, including mild acid hydrolysis (Han et al. 1982), alkaline cleavage (Chen et al. 1987), microbial transformation (Bae et al. 2002; Chi and Ji 2005), and enzymatic transformation (Park et al. 2010; Yang et al. 2015). However, the chemical methods such as mild acid hydrolysis and alkaline cleavage result in undesirable side reactions, such as epimerization, hydration, hydroxylation, and random hydrolysis of glycosidic linkages (Wandrey et al. 2000). Although many studies have been carried out to produce minor ginsenosides from major ginsenosides by microbial and enzymatic methods (Park et al. 2010; Yang et al. 2015), some of microbial methods were limited by safety problems for food application and also some of enzymatic biotransformation methods have serious limitation owing to little or no activity toward G-Rc, C-Mc1 which harbor $\alpha$-L-arabinofuranosyl moiety and low yields (Park et al. 2010).
The fruiting bodies of basidiomycete mushrooms have been used in many cuisines worldwide as food ingredients and some mushrooms have long been used in traditional Chinese medicine (Chen et al. 2015). Mushrooms are fungi of great interest that secrete various hydrolytic enzymes such as cellulase, $\beta$-glucosidase, and endo- and exoglucanase (Buswell et al. 1996; Baldrian and Valášková 2008; Mfombep et al. 2013). Previous study (Upadhyaya et al. 2016) reported that $\mathrm{C}-\mathrm{K}$ was found to be produced with high yield from G-Rb1 by ammonium sulfate (30$80 \%)$ precipitate isolated from the cultured mycelia of Armillaria mellea (AMMEP). Therefore, we investigated the possibility of producing minor ginsenosides from G-Rc, one of major PPD-type ginsenosides (Fig. 1), by using ammonium sulfate $(30-80 \%)$ precipitates isolated from the cultured mycelia of five edible and/or medicinal mushrooms. And then we found that AMMEP have a strong hydrolytic activity of G-Rc into the minor ginsenosides, C-Mc and C-K. C-K has received increasing attention because of its pharmacological activities, for example, anti-inflammatory, anticarcinogenic, antiangiogenesis, antiaging, antiallergic, antidiabetic, and hepatoprotective effects, whereas relatively little is known about the pharmacological activity of C-Mc, except for its antiinflammatory activity in vitro (Bae et al. 2002). In this study, $\beta$-glucosidase (BG-1) which specifically hydrolyzes G-Rc into C-Mc and C-K was homogeneously purified from $A$. mellea mycelia. In addition, the hydrolytic properties of G-Rc by a purified BG-1 were characterized.

\section{Materials and methods \\ Materials}

Strains of A. mellea (KACC 50013), Ganoderma lucidum (KACC 42231), Phellinus baumii (KACC 53719), Ganoderma applanata (KACC 53688), and Pleurotus ostreatus (KACC 50356) were donated by the Korean Agricultural Culture Collection (KACC, Suwon, Gyeonggi-Do, Republic of Korea). G-Rc was isolated from the total crude ginseng saponin fraction according to the reported procedure (Sanada et al. 1974). The purified compound was identified by comparison of spectral data and retention time by HPLC with that of an authentic sample. Authentic standard mixture of G-Rb1, Rb2, G-Rc, G-Rd, G-Rg3 (S), G-F2, C-K, C-Mc1 and C-Mc were freely obtained from the Korea Ginseng Corporation Research Institute (Daejeon, Republic of Korea). $p$-Nitrophenol, $p$-nitrophenyl $(p \mathrm{NP})-\beta$-D-glucopyranoside, $\quad p \mathrm{NP}-\alpha-\mathrm{D}$-glucopyranoside, $p$ NP- $\beta$-D-galactopyranoside, $p$ NP- $\alpha$-D-galactopyranoside, $p \mathrm{NP}-\alpha$-L-arabinofuranoside, $p \mathrm{NP}-\alpha-\mathrm{L}$-arabinopyranoside, DEAE cellulose, Sephadex G-150, bovine serum albumin (BSA) and 4-methylumbelliferyl- $\beta$-D-glucopyranoside (MUG) were purchased from Sigma-Aldrich Co. (St. Louis, MO, USA). Mini-protean TGX precast gel and 
prestaind protein standards for SDS-PAGE was purchased from Bio-RAD (Hercules, CA, USA). Diaion HP-20 resin $(250-850 \mu \mathrm{m})$ was purchased from Supelco Co. (Bellefonte, PA, USA). Silica gel $60 \mathrm{~F}_{254}$ TLC plates and silica gel 60 (230-400 mesh) for column chromatography were purchased from Merck Co. (Darmstadt, Germany). Other reagents were of analytical reagent grade from commercial sources.

\section{Cultivation of mushroom mycelia}

Mushroom mycelia were cultivated following the procedure described in our previous paper (Upadhyaya et al. 2016). Strains were pre-incubated on potato dextrose agar (Becton, Dickinson and Company, Sparks, MD, USA) for 6 days at $25^{\circ} \mathrm{C}$. All nutrient media were sterilized at $121{ }^{\circ} \mathrm{C}$ for $30 \mathrm{~min}$. The pre-incubated strain was inoculated into germinated-malt medium $\left(11 \mathrm{Brix}^{\circ}\right)$ saccharified at $65{ }^{\circ} \mathrm{C}$ with fourfold tap water (v/v) for $8 \mathrm{~h}$, then cultured for 2 weeks at $25^{\circ} \mathrm{C}$. Scaled-up production of mushroom mycelia except for A. mellea was performed in 41 Erlenmeyer flasks containing 11 of germinated-malt medium $\left(11 \mathrm{Brix}^{\circ}\right)$ for 3 weeks at $25-26{ }^{\circ} \mathrm{C}$ with gentle shaking (120 rpm). Standing liquid culture of $\mathrm{A}$. mellea mycelium was performed at $25-26^{\circ} \mathrm{C}$ for 3 weeks in polypropylene bottles $(1.2 \mathrm{l})$ for mushroom cultivation filled with $800 \mathrm{ml}$ of saccharified malt medium (11 Brix ${ }^{\circ}$.

\section{Preparation of crude enzymes}

All procedure for enzyme purification was carried out at room temperature unless otherwise indicated. Culture media was filtered through cheese cloth to separate the mycelia from the broth. The mycelial mass was washed with distilled water to remove residual broth, and then lyophilized. Fifty gram of each lyophilized mycelial mass was mixed with $500 \mathrm{ml}$ of $0.1 \mathrm{M}$ sodium phosphate buffer (pH 4.8) with gentle stirring for $12 \mathrm{~h}$ at $4{ }^{\circ} \mathrm{C}$, then homogenized with an Omni mixer homogenizer (Omni International, Kennesaw, GA, USA) for $1 \mathrm{~min}$ at $4{ }^{\circ} \mathrm{C}$. The slurry was squeezed through cheese cloth and the filtrate was centrifuged at $10,000 \times g$ for $20 \mathrm{~min}$ at $4{ }^{\circ} \mathrm{C}$. Solid ammonium sulfate was added to the supernatant $(400 \mathrm{ml})$, initially to $30 \%$ and eventually to $80 \%$ saturation. After centrifugation at $10,000 \times g$ for $20 \mathrm{~min}$ at $4{ }^{\circ} \mathrm{C}$, the precipitate was dissolved in $10 \mathrm{mM}$ sodium acetate buffer ( $\mathrm{pH}$ 4.8). After overnight dialysis, the solution was centrifuged at $10,000 \times g$ for $20 \mathrm{~min}$ at $4{ }^{\circ} \mathrm{C}$, and the supernatant was lyophilized.

Purification of $\beta$-glucosidase (BG-1) from A. mellea mycelia One hundred gram of lyophilized mycelial mass of $A$. mellea was mixed with $1 \mathrm{l}$ of $0.1 \mathrm{M}$ acetate buffer $(\mathrm{pH} 4.8)$ with gentle stirring for $12 \mathrm{~h}$ at $4{ }^{\circ} \mathrm{C}$, then homogenized with an Omni mixer homogenizer for $1 \mathrm{~min}$ at $4{ }^{\circ} \mathrm{C}$. The slurry was squeezed through cheese cloth and the filtrate was centrifuged at $10,000 \times g$ for $20 \mathrm{~min}$ at $4{ }^{\circ} \mathrm{C}$. Solid ammonium sulfate was added to the supernatant, initially to $30 \%$ and eventually to $80 \%$ saturation. After centrifugation at $10,000 \times g$ for $20 \mathrm{~min}$ at $4{ }^{\circ} \mathrm{C}$, the precipitate was dissolved in $10 \mathrm{mM}$ sodium acetate buffer $(\mathrm{pH}$ 4.8). The concentrated extract $(30 \mathrm{ml})$ was loaded onto a DEAE cellulose column $(18 \mathrm{~cm} \times 3.0 \mathrm{~cm})$ pre-equilibrated with $10 \mathrm{mM}$ acetate buffer ( $\mathrm{pH} 4.8$ ). The column was washed with same buffer for $20 \mathrm{~min}$, and thereafter the bound proteins were eluted with linear gradient condition of $0-0.5 \mathrm{M} \mathrm{NaCl}$ at a flow rate of $1 \mathrm{ml} \mathrm{min}^{-1}$, and fractionated into $3.0 \mathrm{ml}$ per tube. The active fractions were pooled, dialyzed against $10 \mathrm{mM}$ acetate buffer (pH 4.8) using 14 kDa cut-off dialysis tube (Viskase Co., Lombard, IL, USA), and was concentrated by lyophilization. The concentrate was applied to Sephadex G-150 column $(70 \mathrm{~cm} \times 1.8 \mathrm{~cm})$ pre-equilibrated with $10 \mathrm{mM}$ acetate buffer $(\mathrm{pH} 4.8)$ and the fraction were collected at a flow rate of $0.4 \mathrm{ml} \mathrm{min}^{-1}$. The fraction containing $\beta$-glucosidase activity was pooled and lyophilized for further characterization.

\section{Electrophoretic analysis}

Sodium dodecyl sulfate-polyacrylamide gel electrophoresis (SDS-PAGE) was performed with a $12 \%$ mini-protean TGX precast gel at a constant current of $110 \mathrm{~mA}$ according to the method of Laemmli (1970). The gel was stained with Coomassie brilliant blue R-250 and destained with a mixture of $10 \%$ methanol and $10 \%$ acetic acid in distilled water. Native PAGE was performed with a $12 \%$ mini-protean TGX precast gel under the above condition. After electrophoresis, the gel was immersed in $0.1 \mathrm{M}$ acetate buffer $(\mathrm{pH} 4.8)$ containing $0.1 \%$ 4-methylumbelliferyl- $\beta$-D-glucopyranoside (MUG) as a substrate for $30 \mathrm{~min}$ at $37^{\circ} \mathrm{C}$. The aglycone liberated was detected under ultraviolet (UV) light (365 nm).

\section{Enzyme assays}

$\beta$-Glucosidase activity was assayed as described by Mfombep et al. (2013) with some modifications. Briefly, the reaction mixture $(1.0 \mathrm{ml})$, containing $0.1 \mathrm{ml}$ of $p \mathrm{NP}-\beta$-D-glucopyranoside $(10 \mathrm{mM}), 0.1 \mathrm{ml}$ of appropriately diluted enzyme solution, and $0.8 \mathrm{ml}$ of $0.1 \mathrm{M}$ acetate buffer ( $\mathrm{pH} 4.8$ ), was incubated for $30 \mathrm{~min}$ at $37^{\circ} \mathrm{C}$. The reaction was terminated by adding $1.0 \mathrm{ml}$ of $0.5 \mathrm{M}$ $\mathrm{Na}_{2} \mathrm{CO}_{3}$ solution. The released $p$-nitrophenol was measured immediately using a UV-visible spectrophotometer (UV-1601, Shimadzu, Tokyo, Japan) at $400 \mathrm{~nm}$. Activities toward other $p \mathrm{NP}$ glycosides were assayed in the same way. The amount of $p$-nitrophenol released was quantified using a concentration plot of a $p$-nitrophenol standard. One unit of enzyme activities were defined as the 
amount of enzyme required to release $1 \mu \mathrm{M}$ of $p$-nitrophenol $\mathrm{min}^{-1}$ under the assay conditions.

\section{Enzymatic hydrolysis of G-Rc and enzyme characterization} The reaction mixture $(2.0 \mathrm{ml})$ containing $2.0 \mathrm{mg}$ of G-Rb1, G-Rc or G-Rd in $0.2 \mathrm{ml}$ of methanol and each enzyme solution showing $1.5 \mathrm{U}$ of $\beta$-glucosidase activity in $1.8 \mathrm{ml}$ of $0.1 \mathrm{M}$ sodium acetate buffer $(\mathrm{pH} 4.8)$ were incubated for $96 \mathrm{~h}$ at $45{ }^{\circ} \mathrm{C}$, respectively. The reaction mixture was extracted twice with $2.0 \mathrm{ml}$ of water saturated $n$-butanol. The $n$-butanol fraction was concentrated to dryness in vacuo, and the residue was dissolved in $1.0 \mathrm{ml}$ of methanol. To investigate the time course of G-Rc hydrolysis by $\beta$-glucosidase (BG-1) purified from A. mellea mycelia, $20 \mathrm{ml}$ of reaction mixture containing $20 \mathrm{mg}$ of G-Rc in $2.0 \mathrm{ml}$ methanol, enzyme solution containing $15 \mathrm{U}$ of BG-1 and $0.1 \mathrm{M}$ sodium acetate buffer (pH 4.8) was incubated for $96 \mathrm{~h}$ at $45^{\circ} \mathrm{C}$ with gentle shaking. Two milliliters of the reaction mixture were withdrawn at regular time intervals, and extracted twice with $2.0 \mathrm{ml}$ of water saturated $n$-butanol. The $n$-butanol fraction was concentrated to dryness in vacuo. The residue was dissolved in $1.0 \mathrm{ml}$ of methanol, and was subjected to TLC and HPLC analysis.

The effect of temperature on hydrolytic activity of G-Rc was examined by incubating the reaction mixture at temperatures ranging from 30 to $70{ }^{\circ} \mathrm{C}$ for $96 \mathrm{~h}$ at $\mathrm{pH} 4.8$. The effect of $\mathrm{pH}$ was examined using G-Rc as a substrate for $96 \mathrm{~h}$ at $45{ }^{\circ} \mathrm{C}$ in the following buffer solutions (each at $0.1 \mathrm{M})$ : glycine- $\mathrm{HCl}(\mathrm{pH} 3.0)$, sodium acetate $(\mathrm{pH} 4.0$, $4.5,5.0,5.5)$, sodium phosphate $(\mathrm{pH} 6.0$ and 7.0), Tris$\mathrm{HCl}(\mathrm{pH} 8.0)$, and glycine- $\mathrm{NaOH}$ ( $\mathrm{pH}$ 9.0). To investigate the effect of enzyme concentration, the enzyme solutions containing $\beta$-glucosidase activity ranging from 0.1 to $1.6 \mathrm{U}$ in $1.8 \mathrm{ml}$ of $0.1 \mathrm{M}$ sodium acetate buffer $(\mathrm{pH} 4.8)$ were incubated with $2.0 \mathrm{mg}$ of G-Rc in $0.2 \mathrm{ml}$ of methanol for $96 \mathrm{~h}$ at $45^{\circ} \mathrm{C}$. The relative ratio of hydrolysis products in the reaction mixtures were calculated from the peak area percentages in HPLC analysis without consideration of the detector response factor. All experiments were performed in triplicate, and the data are expressed as the mean \pm standard deviation (SD).

\section{Isolation and identification of hydrolysis products}

A reaction mixture containing $0.6 \mathrm{~g}$ of G-Rc in $10 \mathrm{ml}$ of methanol, enzyme solution containing $450 \mathrm{U}$ of BG-1, and $290 \mathrm{ml}$ of $0.1 \mathrm{M}$ sodium acetate buffer $(\mathrm{pH} 4.8)$, making the final volume of $300 \mathrm{ml}$, was incubated for $24 \mathrm{~h}$ at $45^{\circ} \mathrm{C}$ with gentle stirring. After a 10 min heattreatment in boiling water, the reaction mixture was passed through a Diaion HP-20 column $(40 \mathrm{~cm} \times 4 \mathrm{~cm})$ at a flow rate of $4 \mathrm{ml} \mathrm{min}^{-1}$. The resin was washed with $500 \mathrm{ml}$ of distilled water to remove water soluble sugars.
The hydrolysis products were eluted from the resin with $400 \mathrm{ml}$ of methanol. The eluate was then concentrated to dryness in vacuo. The concentrate was chromatographed on a silica gel column using stepwise gradient elution with chloroform-methanol-water (90:10:0.5 $\rightarrow$ 80:20:2 $\rightarrow 60: 35: 10, \mathrm{v} / \mathrm{v} / \mathrm{v}$, lower phase). The yields of metabolites S1, S2, S3, S4, and S5 were 35, 23, 18, 24, and $23 \mathrm{mg}$, respectively.

\section{TLC analysis}

TLC was performed on silica gel $60 \mathrm{~F}_{254}$ with chloroform-methanol-water $(65: 35: 10, \mathrm{v} / \mathrm{v} / \mathrm{v}$, lower phase) as the developing solvent. The spots on the TLC were detected by spraying $10 \%(\mathrm{w} / \mathrm{v})$ sulfuric acid in ethanol, followed by heating at $110{ }^{\circ} \mathrm{C}$ for $10 \mathrm{~min}$.

\section{HPLC and UPLC/Q-TOF-MS analysis}

HPLC analysis was performed using an HPLC system (Waters, Milford, MA, USA) equipped with a $600 \mathrm{E}$ system controller, 717 plus autosampler and 486 UV detector $(203 \mathrm{~nm})$ with a YMC $\mathrm{C}_{18}$ column (250 mm × $4.6 \mathrm{~mm}, 5 \mu \mathrm{m}$, YMC Co. Ltd., Tokyo, Japan). The mobile phase consisted of water (A) and acetonitrile (B) at ratios of A:B 70:30 (0-15 min), 43:57 (15$25 \mathrm{~min}), 30: 70(25-30 \mathrm{~min})$, and $70: 30(30-35 \mathrm{~min})$ at a flow rate of $0.9 \mathrm{ml} \mathrm{min}^{-1}$. UPLC/Q-TOF-MS analysis was performed using a Waters ACQUITY UPLC system composed of a binary solvent manager and a photo diode array detector $(203 \mathrm{~nm})$. The chromatographic separation was performed on an ACQUITY UPLC BEH $\mathrm{C}_{18}$ column $(100 \mathrm{~mm} \times 2.1 \mathrm{~mm}, 1.7 \mu \mathrm{m})$. The column temperature was $40{ }^{\circ} \mathrm{C}$. The binary gradient elution system consisted of $0.001 \%$ phosphoric acid in water (A) and $0.001 \%$ phosphoric acid in acetonitrile (B). The separation was achieved using the following gradient program of $\mathrm{A}: \mathrm{B}=85: 15$ (0-0.5 min), 70:30 (14.5 min), 68:32 (15.5 min), 62:38 (18.5 min), 57:43 (24.0 $\mathrm{min}), 45: 55$ (31.0 $\mathrm{min}), 30: 70$ (35.0 $\mathrm{min}), 10: 90$ (38.0 min), 85:15 (43.0 min) (Park et al. 2013). The flow rate was $0.6 \mathrm{ml} \mathrm{min}{ }^{-1}$. MS analysis was performed on a Waters Xevo quadruple-time of flight mass spectrometer (Q-TOF-MS) equipped with an electrospray ionization (ESI) source in negative ion mode. The conditions for MS analysis were: drying gas $\mathrm{N}_{2}$, flow rate $121 \mathrm{~min}^{-1}$, cone gas temperature $350{ }^{\circ} \mathrm{C}$, nebulizer pressure $50 \mathrm{psi}$, and capillary voltage $4.0 \mathrm{kV}$.

\section{NMR analysis}

NMR spectra were taken on a JEOL model JNM-ECA 600 FT-NMR spectrometer (Akishima, Tokyo, Japan) at $600 \mathrm{MHz}\left({ }^{1} \mathrm{H} \mathrm{NMR}\right)$ and $150 \mathrm{MHz}\left({ }^{13} \mathrm{C} \mathrm{NMR}\right)$ in pyridine- $\mathrm{d}_{5}$ with tetramethylsilane as an internal standard. 


\section{Results}

Purification of $\beta$-glucosidase from A. mellea mycelia

Five edible and/or medicinal mushrooms were screened for their ability to hydrolyze G-Rc into minor ginsenosides. The result showed that $\mathrm{C}-\mathrm{Mc}$ and $\mathrm{C}-\mathrm{K}$ were efficiently produced from G-Rc by crude enzyme preparations from $A$. mellea mycelia, whereas crude enzyme preparations from G. lucidum, P. baumii, G. applanata, and $P$. ostreatus produced of G-Rd as a final product (Fig. 2). Armillaria mellea mycelia has potential to be used to prepare minor ginsenosides such as C-Mc and $\mathrm{C}-\mathrm{K}$ with high yield from G-Rc, and was chosen for further study.

$\beta$-Glucosidases in ammonium sulfate precipitate isolated from $A$. mellea mycelia were eluted as three active fractions by DEAE cellulose ion exchange chromatography (Fig. 3a). These enzymes in relevant fraction were designated as BG-1, BG-2 and BG-3, respectively. The results indicate that $A$. mellea $\beta$-glucosidases exist in three isomeric forms that they exhibited different retention behaviors on DEAE cellulose column and different hydrolytic activity toward $p$ NP- $\beta$-D-glucopyranoside. BG-1 was further purified by Sephadex G-150 gel chromatography (Fig. 3b). Finally, the BG-1 was purified approximately 34 fold with a yield of $1.44 \%$ relative to the crude enzyme extract. When G-Rb1, G-Rc and G-Rd were used as the substrates, BG-1 showed

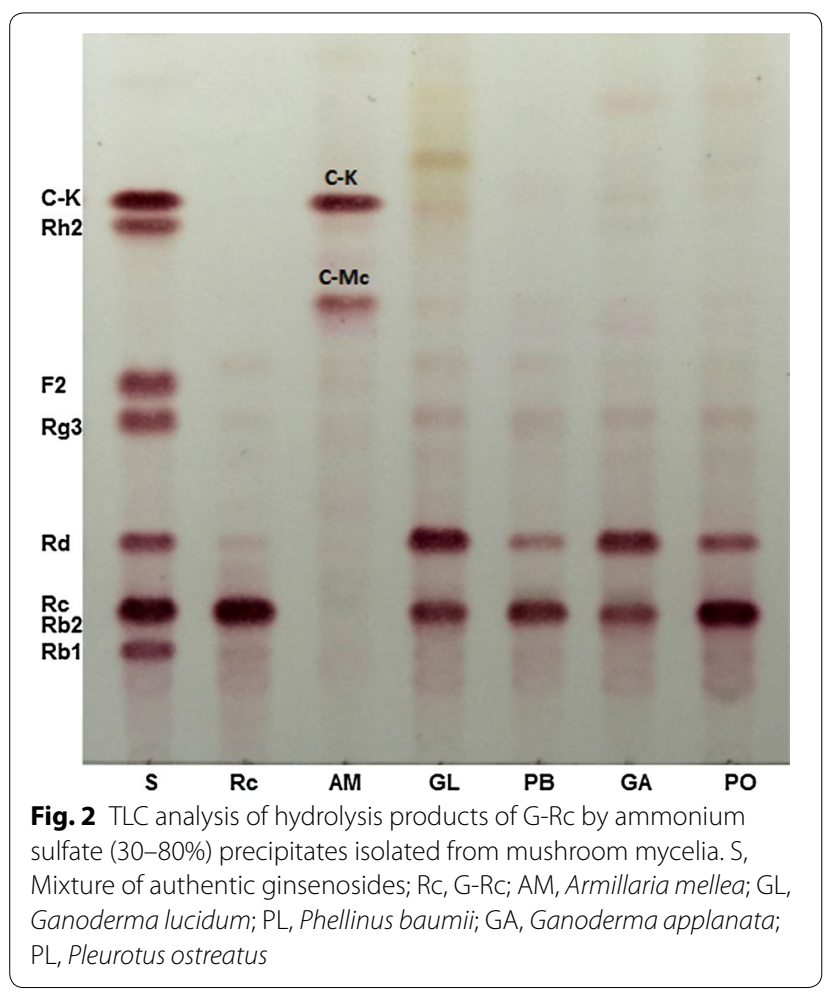

different hydrolytic patterns from those of BG-2 and BG-3 with potent hydrolytic activity toward G-Rc (Fig. 4). The specific activity of the purified enzyme was $17.9 \mathrm{U} \mathrm{mg}^{-1}$ protein. BG-1 was purified to homogeneity as shown by both SDS-PAGE and native PAGE (Fig. 5a). Compared with protein markers, the molecular weight of BG-1 was estimated as $121.5 \mathrm{kDa}$ on SDS-PAGE (Fig. 5b). A summary of the purification result is shown in Table 1 . When substrate specificities of BG-1 were as assayed using of $p$ NP-glycosides with $\alpha$ - and $\beta$-configurations. BG-1 showed hydrolytic activities toward $p \mathrm{NP}-\alpha-\mathrm{L}$-arabinofurnoside and $p \mathrm{NP}-\alpha-$ L-arabinopyranoside besides $p \mathrm{NP}-\beta$-D-glucopyranoside, but not toward $p \mathrm{NP}-\alpha-\mathrm{D}$-glucopyranoside and $p \mathrm{NP}-\alpha-$ and - $\beta$-galactopyranoside (Table 2 ).

\section{Isolation and identification of hydrolysis products}

To investigate the hydrolysis pattern of G-Rc by BG-1 with reaction time, the reaction mixture was withdrawn at regular time intervals during the enzymatic hydrolysis. TLC (Fig. 6a) and HPLC (Fig. 6b) profiles showed that G-Rc was gradually hydrolyzed to five compounds (hydrolysis products S1, S2, S3, S4, and S5). G-Rc was hydrolyzed into $\mathrm{S} 1$ and $\mathrm{S} 2$ in the early stage of the reaction (within $24 \mathrm{~h}$ ). After $96 \mathrm{~h}$ reaction, almost all of the G-Rc and products S1, S2 and S3 were hydrolyzed into products S4 and S5 (Fig. 7). These new spots were not observed when the reaction mixture containing only G-Rc was incubated in for $96 \mathrm{~h}$ at $45^{\circ} \mathrm{C}$ and a $10 \mathrm{~min}$ heat-treatment in boiling water. These results suggest that products $\mathrm{S} 1, \mathrm{~S} 2$, and $\mathrm{S} 3$ were intermediate products, while S4 and S5 were final hydrolysis products. The mixture after $24 \mathrm{~h}$ reaction was analyzed by UPLC/Q-TOFMS, and the products were isolated in a pure state by repeated silica gel column chromatography to determine their chemical structures.

Product S1 appeared as a quasi-molecular ion peak at $m / z 991.5038[\mathrm{M}-\mathrm{H}+\mathrm{HCOOH}]^{-}$with a molecular ion peak $[\mathrm{M}-\mathrm{H}]^{-}$at $m / z 945.5298$ by Q-TOF-LC/ MS analysis, corresponding to the molecular formula $\mathrm{C}_{48} \mathrm{H}_{82} \mathrm{O}_{18}$ (MW 946.5501). The ${ }^{1} \mathrm{H}$-NMR spectrum of $\mathrm{S} 1$ showed eight methyl signals assignable to an aglycone part at $\delta_{\mathrm{H}}\left(\mathrm{C}_{5} \mathrm{D}_{5} \mathrm{~N}\right) 0.80,0.94,0.96,1.11,1.28,1.60$, 1.60 , and 1.63 (all $3 \mathrm{H}$, all s), and anomeric proton signals due to three $\beta$-glucosidic linkages at $\delta_{\mathrm{H}} 4.93(1 \mathrm{H}$, $\mathrm{d}, J=7.42 \mathrm{~Hz}, \mathrm{H}-1$ of inner glucose at C-3 of aglycone), $\delta_{\mathrm{H}} 5.15(1 \mathrm{H}, \mathrm{d}, J=7.60 \mathrm{~Hz}, \mathrm{H}-1$ of glucose at C-20 of aglycone), and $\delta_{\mathrm{H}} 5.39(1 \mathrm{H}, \mathrm{d}, J=7.56 \mathrm{~Hz}, \mathrm{H}-1$ of outer glucose at $\mathrm{C}-3$ of aglycone). The ${ }^{13} \mathrm{C}$-NMR spectrum of $\mathrm{S} 1$ showed three anomeric carbon signals at $\delta_{\mathrm{C}} 98.1$, 105.0, and 105.9 with 30 carbon signals ascribable to aglycone and 18 carbon signals ascribable to three glucoses (Table 3). Accordingly, S1 was determined to be 


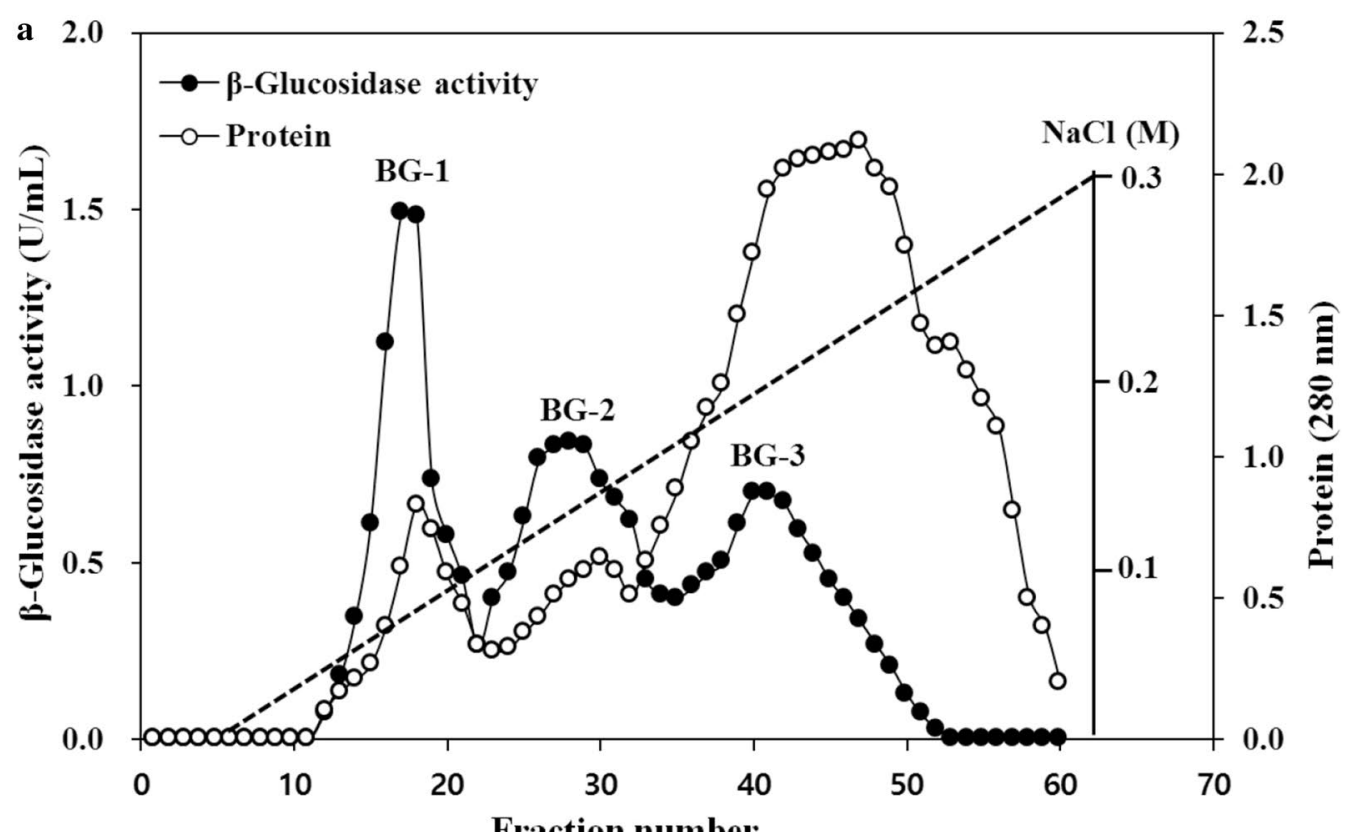

Fraction number

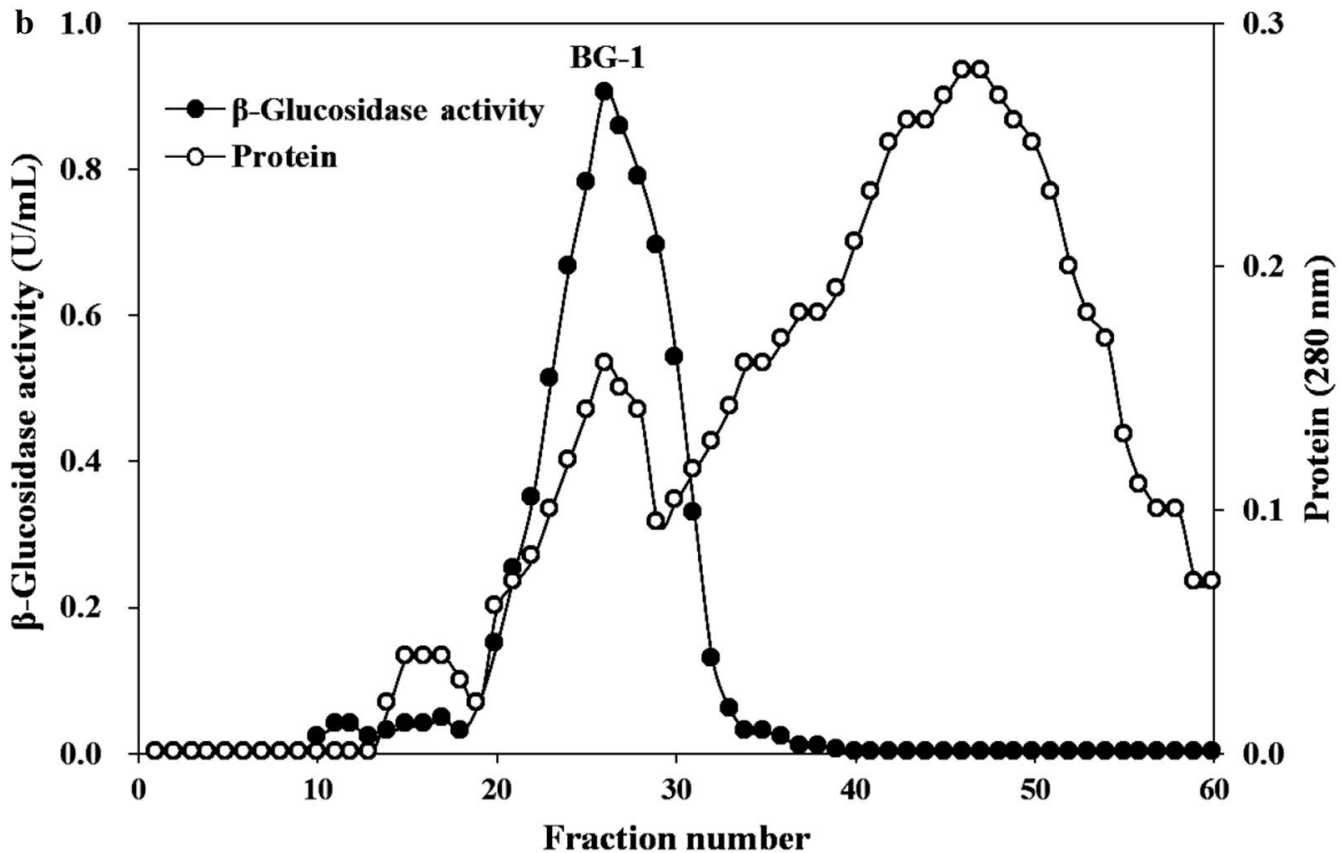

Fig. 3 a DEAE cellulose ion exchange chromatography. b Sephadex G-150 gel chromatography

3-O-[ $\beta$-D-glucopyranosyl- $(1 \rightarrow 2)$ - $\beta$-D-glucopyranosyl]20-O- $\beta$-D-glucopyranosyl-20(S)-protopanaxadiol (G-Rd).

$\mathrm{S} 2$ showed quasi-molecular ion peaks at $\mathrm{m} / \mathrm{z} 961.4637$ $[\mathrm{M}-\mathrm{H}+\mathrm{HCOOH}]^{-}$and $915.5251[\mathrm{M}-\mathrm{H}]^{-}$by UPLC/ Q-TOF-MS analysis, corresponding to the molecular formula $\mathrm{C}_{47} \mathrm{H}_{80} \mathrm{O}_{17}$ (MW 916.5396). The ${ }^{1} \mathrm{H}$-NMR spectrum of $\mathrm{S} 2$ showed eight methyl signals assignable to an aglycone part at $\delta_{\mathrm{H}} 0.75,0.90,0.92,0.96,1.33,1.56$,
1.56, and 1.59 (all $3 \mathrm{H}$, all $\mathrm{s}$ ), and three anomeric proton signals due to two $\beta$-glucosidic linkages at $\delta_{\mathrm{H}} 4.95$ $(1 \mathrm{H}, \mathrm{d}, J=7.60 \mathrm{~Hz})$ and $5.15(1 \mathrm{H}, \mathrm{d}, J=7.90 \mathrm{~Hz})$ and one $\alpha$-arabinofuranosidic linkage at $\delta_{\mathrm{H}} 5.69(1 \mathrm{H}, \mathrm{d}$, $J=1.72 \mathrm{~Hz}, \mathrm{H}-1$ of outer arabinofuranose at C-20 of aglycone). In ${ }^{13} \mathrm{C}-\mathrm{NMR}$ chemical shifts (Table 3), three anomeric carbon signals were observed, at $\delta_{C} 98.5$ and 105.0 due to two $\beta$-glucosidic linkages, and $\delta_{C} 110.5$ due 


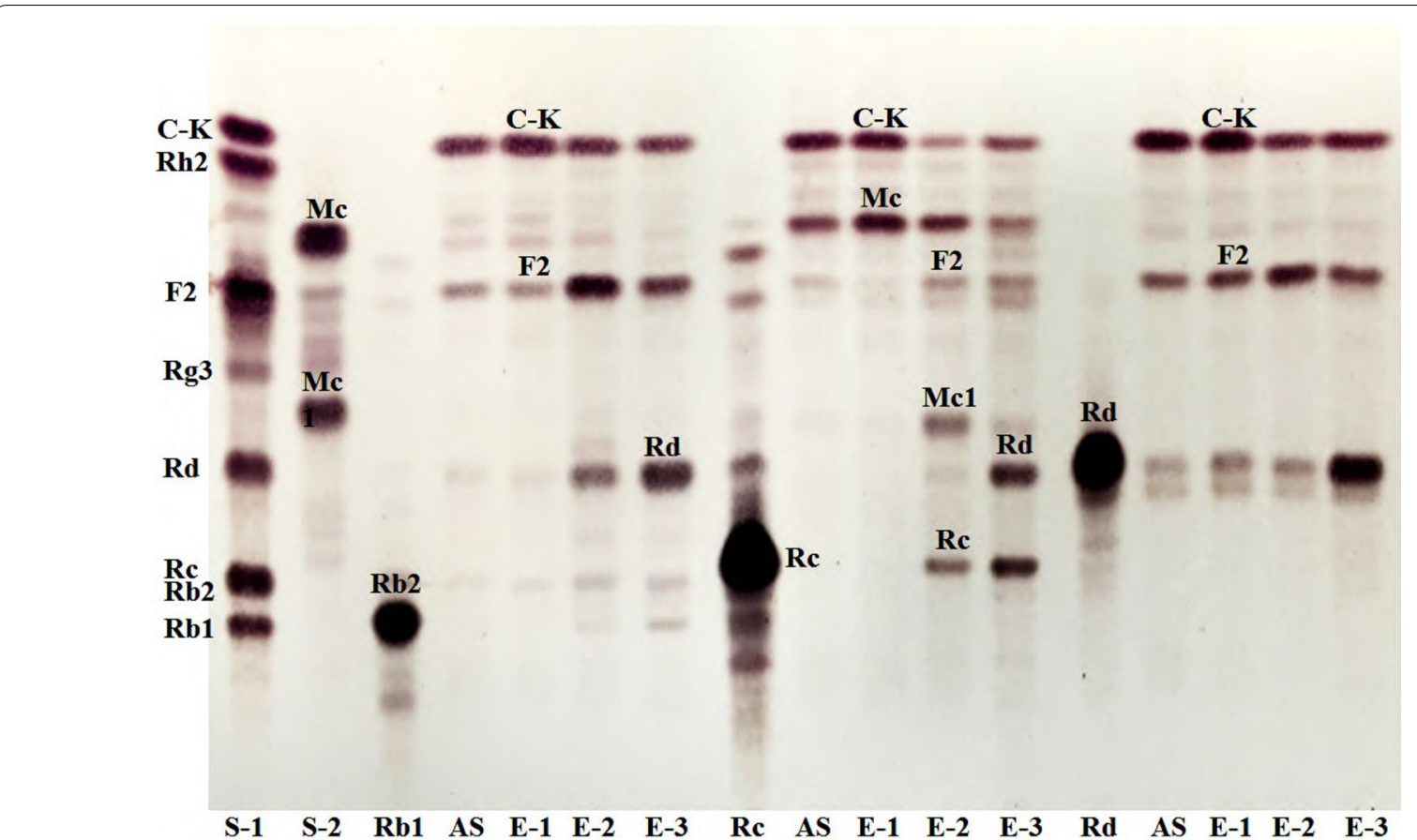

Fig. 4 TLC analysis of hydrolysis products of G-Rb1, G-Rc and G-Rd by AS (30-80\% ammonium sulfate precipitate); E-1 (BG-1); E-2 (BG-2); E-3 (BG-3)

to one $\alpha$-arabinofuranosidic linkage. Therefore, product S2 was identified as 3-O- $\beta$-D-glucopyranosyl-20-O- $[\alpha-$ L-arabinofuranosyl-(1-6)- $\beta$-D-glucopyranosyl]-20(S)protopanaxadiol (C-Mc1).

S3 showed a quasi-molecular ion peak at $m / z 829.4857$ $[\mathrm{M}-\mathrm{H}+\mathrm{HCOOH}]^{-}$by UPLC/Q-TOF-MS analysis, corresponding to the molecular formula $\mathrm{C}_{42} \mathrm{H}_{72} \mathrm{O}_{13}$ (MW 784.4973). The ${ }^{1} \mathrm{H}-\mathrm{NMR}$ spectrum of $\mathrm{S} 3$ showed eight methyl signals assignable to an aglycone part at $\delta_{\mathrm{H}} 0.79$, $0.92,0.94,0.97,1.30,1.58,1.58$, and 1.61 (all $3 \mathrm{H}$, all s) and two anomeric proton signals due to $\beta$-glucosidic linkages at $\delta_{\mathrm{H}} 4.93(1 \mathrm{H}, \mathrm{d}, J=7.02 \mathrm{~Hz}$, glucose at C-3 position of aglycone) and $\delta_{\mathrm{H}} 5.22(1 \mathrm{H}, \mathrm{d}, J=7.32 \mathrm{~Hz}$, glucose at C-20 position of aglycone). There were two anomeric carbon signals at $\delta_{\mathrm{C}} 98.1$ and 106.7 due to $\beta$-glucosidic linkages in the ${ }^{13} \mathrm{C}$-NMR spectrum. Therefore, S3 was identified as $3-O-\beta$-D-glucopyranosyl-20-O- $\beta$-D-glucopyranosyl20(S)-protopanaxadiol (G-F2).

S4, one of the two final products, showed quasi-molecular ion peaks at $799.4570[\mathrm{M}-\mathrm{H}+\mathrm{HCOOH}]^{-}$and $753.4780[\mathrm{M}-\mathrm{H}]^{-}$corresponding to the molecular formula $\mathrm{C}_{41} \mathrm{H}_{72} \mathrm{O}_{12}$ (MW 754.4788). The ${ }^{1} \mathrm{H}$-NMR spectrum of S4 showed eight methyl signals assignable to an aglycone part at $\delta_{\mathrm{H}} 0.89,0.94,1.00,1.04,1.23,1.63,1.65$, and 1.67 (all $3 \mathrm{H}$, all s), and two anomeric proton signals due to one $\beta$-glucosidic linkage at $\delta_{\mathrm{H}} 5.15(1 \mathrm{H}, \mathrm{d}$, $J=7.60 \mathrm{~Hz}, \mathrm{H}-1$ of inner glucose at C-20 of aglycone) and one $\alpha$-arabinofuranosidic linkage at $\delta_{\mathrm{H}} 5.67(1 \mathrm{H}, \mathrm{d}$, $J=1.72 \mathrm{~Hz}, \mathrm{H}-1$ of outer arabinofuranose at C-20 of aglycone). In the ${ }^{13} \mathrm{C}$-NMR spectrum, two anomeric carbon signals were observed at $\delta_{C} 98.5$ due to one $\beta$-glucosidic linkage and at $\delta_{\mathrm{C}} 110.5$ due to one $\alpha$-arabinofuranosidic linkage. From these results, product $\mathrm{S} 4$ was determined to be 20-O-[ $\alpha-\mathrm{L}$-arabinofuranosyl-(1-6)- $\beta$-Dglucopyranosyl]-20(S)-protopanaxadiol (C-Mc).

Product S5 showed quasi-molecular ion peaks at $\mathrm{m} / \mathrm{z}$ $667.4309[\mathrm{M}-\mathrm{H}+\mathrm{HCOOH}]^{-}$and $621.4309[\mathrm{M}-\mathrm{H}]^{-}$ by UPLC/Q-TOF-MS analysis, corresponding to the molecular formula $\mathrm{C}_{36} \mathrm{H}_{62} \mathrm{O}_{8}$ (MW 622.4445). The ${ }^{1} \mathrm{H}-\mathrm{NMR}$ spectrum of $\mathrm{S} 5$ showed eight methyl signals assignable to an aglycone part at $\delta_{\mathrm{H}} 0.89,0.95,0.99$, $1.04,1.23,1.60,1.60,1.63$ (all $3 \mathrm{H}$, all s), and one anomeric proton signal due to a $\beta$-glucosidic linkage at $\delta_{\mathrm{H}} 5.18(1 \mathrm{H}, \mathrm{d}, J=7.66 \mathrm{~Hz}$, glucose at $\mathrm{C}-20$ position of aglycone). The ${ }^{13} \mathrm{C}$-NMR spectrum of $\mathrm{S} 5$ showed one anomeric carbon signal at $\delta_{\mathrm{C}} 98.7$ with 30 carbon signals ascribable to aglycone and six carbon signals ascribable to one glucose. The HPLC retention time of S5 was consistent with that of standard C-K. From these results, product $\mathrm{S} 5$ was identified as $20-O-\beta-\mathrm{D}$ glucopyranosyl-20(S)-protopanaxadiol (C-K). The ${ }^{13} \mathrm{C}-$ NMR chemical shifts for compounds in the present study are consistent with previous results (Bae et al. 2002; Liu et al. 2015). 


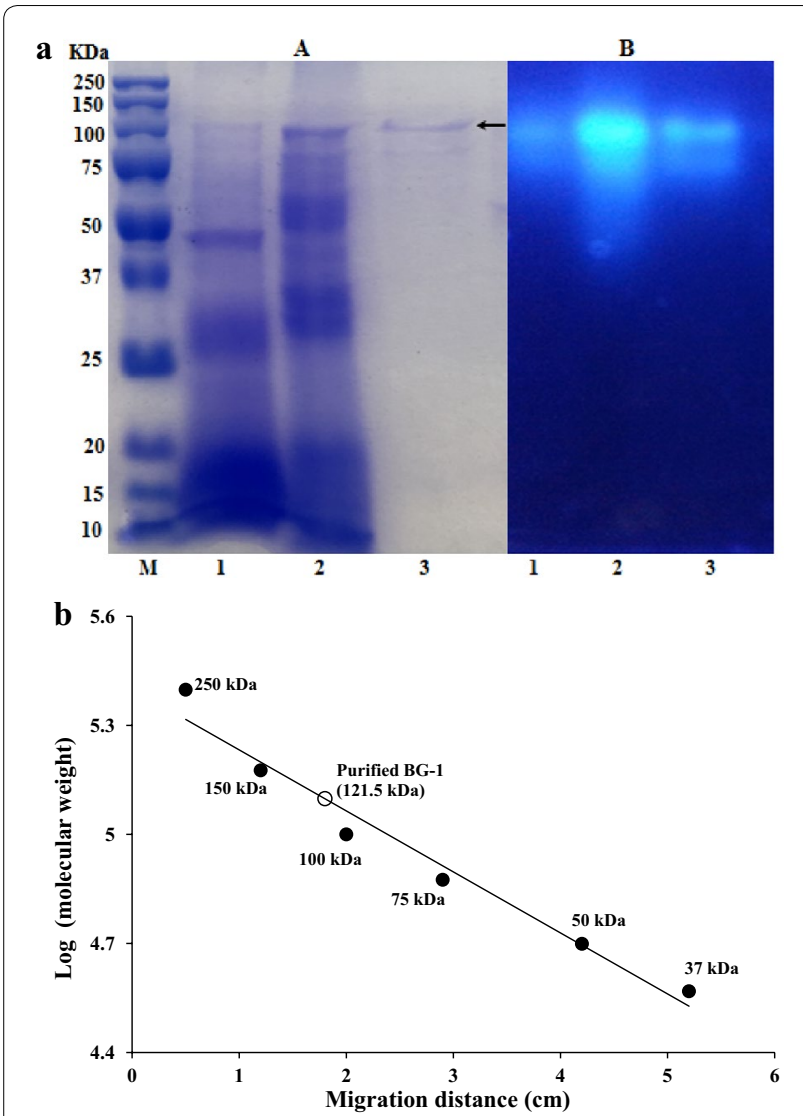

Fig. 5 a SDS-PAGE $(A)$ and native PAGE $(B)$ analysis of the purified BG-1 enzyme. $M$ protein molecular weight marker; lane 1 ammonium sulfate precipitate; lane 2 DEAE cellulose ion exchange chromatography; lane 3 purified BG-1. b Determination of molecular mass of the purified BG-1 by SDS-PAGE

\section{Hydrolytic characterization of G-Rc by BG-1}

When hydrolysis of G-Rc by BG-1 was conducted at various temperatures, the hydrolysis of G-Rc was maximized at $45-60{ }^{\circ} \mathrm{C}$. Interestingly, the optimum temperature for $\mathrm{C}$-Mc and $\mathrm{C}$ - $\mathrm{K}$ formation were slightly different, $55-60{ }^{\circ} \mathrm{C}$ for $\mathrm{C}-\mathrm{Mc}$ and $45-50{ }^{\circ} \mathrm{C}$ for $\mathrm{C}-\mathrm{K}$ (Fig. 8a), respectively. Hydrolysis of G-Rc was decreased at temperatures below $35^{\circ} \mathrm{C}$ and above $65{ }^{\circ} \mathrm{C}$. To investigate the effect of $\mathrm{pH}$ on the hydrolytic activity of G-Rc by BG-1, pH was varied from 3.0 to 9.0 as shown in Fig. 8b. G-Rc was hydrolyzed
Table 2 Relative activity of BG-1 on various chromogenic substrates

\begin{tabular}{|c|c|}
\hline Substrate & Activity (\%) \\
\hline pNP- $\beta$-D-glucopyranoside & 100 \\
\hline pNP-a-D-glucopyranoside & 0 \\
\hline pNP-a-L-arabinopyranoside & 10.2 \\
\hline pNP-a-L-arabinofuranoside & 30.0 \\
\hline pNP- $\beta$-D-galactopyranoside & 0 \\
\hline pNP-a-D-galactopyranoside & 0 \\
\hline
\end{tabular}

Relative activity expressed relative to activity on pNP- $\beta$-D-glucopyranoside (100\%)

into G-Rd, C-Mc1, G-F2, C-Mc, and C-K at pH 3.0. C-Mc and $\mathrm{C}-\mathrm{K}$ formation reached their maxima at $\mathrm{pH} 4.0-4.5$. When the $\mathrm{pH}$ value was increased to $\geq 5.0$, the hydrolytic activity of G-Rc was decreased. These results suggest that the optimum $\mathrm{pH}$ range for hydrolysis of G-Rc by BG-1 is between $\mathrm{pH} 4.0$ and 4.5. The effect of enzyme concentration on the formation of $\mathrm{C}-\mathrm{Mc}$ and $\mathrm{C}-\mathrm{K}$ was examined. As shown in Fig. 9, as the concentration of enzyme in the reaction mixture was increased, the conversion ratio of G-Rc to C-Mc and C-K was increased. When G-Rc (2.0 mg) was incubated with BG-1 containing 0.8-1.6 U of $\beta$-glucosidase activity in the reaction mixture $(1 \mathrm{ml})$ for $96 \mathrm{~h}$ at $45{ }^{\circ} \mathrm{C}, \mathrm{G}-\mathrm{Rc}$ was completely hydrolyzed to $\mathrm{C}-\mathrm{Mc}$ and $\mathrm{C}-\mathrm{K}$.

\section{Hydrolysis pathways of G-Rc by BG-1}

G-Rc has two glucose moieties at the $\mathrm{C}-3$ position of the PPD-type aglycone, and one arabinofuranose and one glucose at the C-20 position. Therefore, G-Rc can be hydrolyzed by $\beta$-glucosidases via multiple pathways. In this study, the results obtained from TLC, HPLC, and UPLC/Q-TOF-MS analysis showed that hydrolysis of G-Rc by BG-1 occurred through two main pathways, as shown in Fig. 10. In one pathway, BG-1 first hydrolyzed the outer $\alpha$-L-arabinofuranosidic linkage attached to the $\mathrm{C}-20$ position of the aglycone to produce G-Rd, followed by hydrolysis of the outer and inner glucose moieties attached to the $\mathrm{C}-3$ position to produce $\mathrm{C}-\mathrm{K}$ via G-F2. Concurrently, in the second pathway, BG-1 hydrolyzed the outer $\beta$-glucosidic linkage attached to the

Table 1 Purification of BG-1 from A. mellea mycelia

\begin{tabular}{|c|c|c|c|c|c|}
\hline & Total protein (mg) & Total activity (U) & $\begin{array}{l}\text { Specific activity (U } \\
\mathrm{mg}^{-1} \text { ) }\end{array}$ & Yield (\%) & Purification (fold) \\
\hline Crude extract & 1119.4 & 595.5 & 0.53 & 100 & 1 \\
\hline $30-80 \%\left(\mathrm{NH}_{4}\right)_{2} \mathrm{SO}_{4}$ & 154.7 & 178.6 & 1.15 & 30.0 & 2.17 \\
\hline DEAE cellulose & 10.6 & 51.8 & 4.89 & 8.70 & 9.23 \\
\hline Sephadex G-150 & 0.48 & 8.60 & 17.9 & 1.44 & 33.8 \\
\hline
\end{tabular}




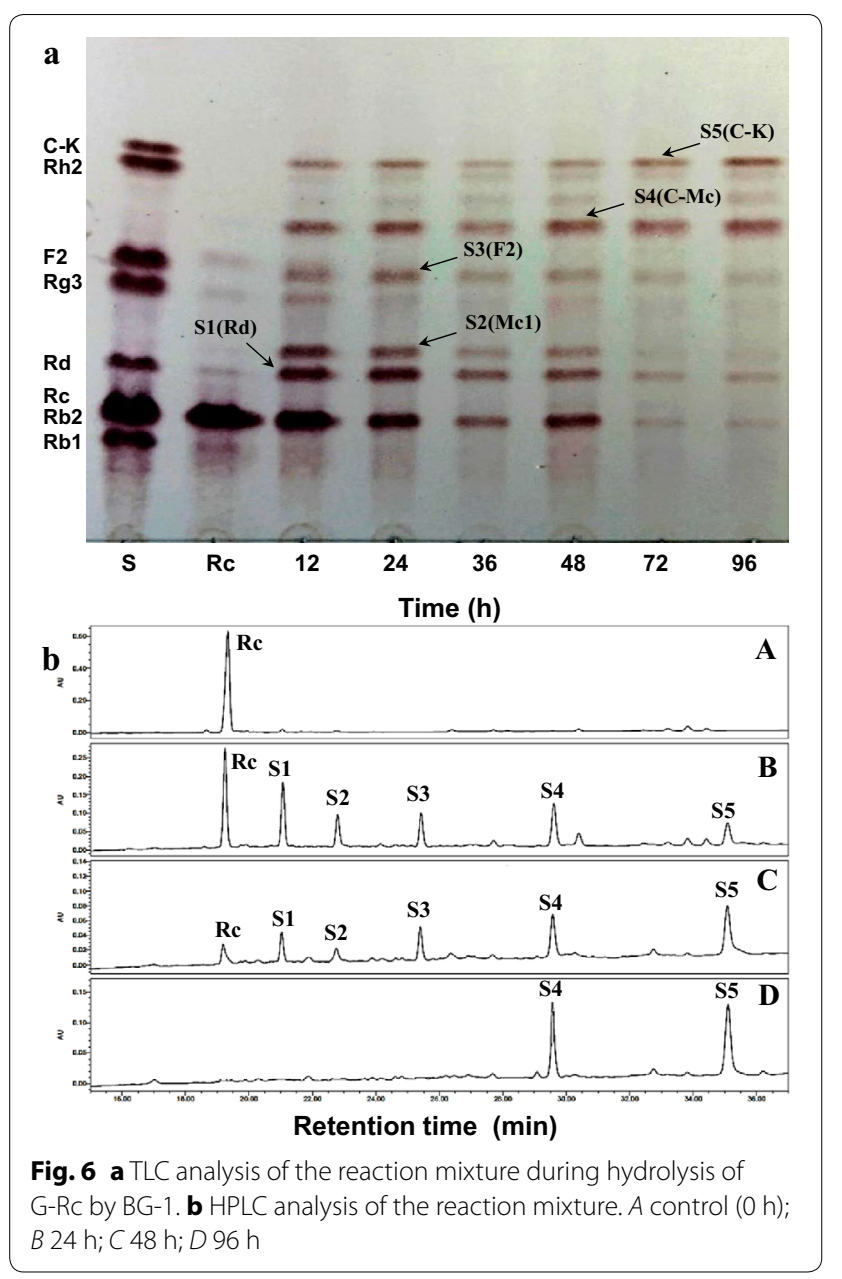

Table $3{ }^{13} \mathrm{C}$-NMR chemical shifts of hydrolysis products of G-Rc by BG-1

\begin{tabular}{llrrrr}
\hline Carbon no & G-Rd & C-Mc1 & G-F2 & C-MC & C-K \\
\hline Aglycone moiety & & & & & \\
1 & 39.0 & 39.6 & 38.9 & 39.9 & 39.8 \\
2 & 26.6 & 27.2 & 26.5 & 26.6 & 26.6 \\
3 & 88.8 & 89.2 & 88.6 & 78.5 & 78.7 \\
4 & 39.5 & 40.1 & 39.5 & 39.8 & 39.9 \\
5 & 56.2 & 56.8 & 56.1 & 56.6 & 56.8 \\
6 & 18.3 & 18.2 & 18.2 & 18.3 & 19.2 \\
7 & 35.0 & 35.5 & 34.9 & 35.6 & 35.6 \\
8 & 39.9 & 40.4 & 39.8 & 40.0 & 40.0 \\
9 & 50.0 & 50.6 & 50.0 & 50.7 & 50.8 \\
10 & 36.7 & 37.3 & 36.7 & 37.8 & 37.8 \\
11 & 30.6 & 30.6 & 30.6 & 30.6 & 31.3 \\
12 & 70.1 & 70.6 & 70.1 & 70.6 & 70.6 \\
13 & 49.3 & 49.8 & 49.5 & 49.9 & 50.0 \\
14 & 51.4 & 52.0 & 51.2 & 51.8 & 52.0 \\
15 & 30.7 & 30.4 & 29.8 & 31.1 & 31.4 \\
16 & 26.5 & 27.0 & 26.4 & 26.2 & 26.3 \\
17 & 51.5 & 51.8 & 51.5 & 52.1 & 51.9 \\
18 & 16.1 & 16.7 & 16.1 & 16.7 & 16.5 \\
19 & 15.8 & 16.4 & 15.7 & 16.5 & 16.8 \\
20 & 83.2 & 82.8 & 83.1 & 83.8 & 83.8 \\
21 & 22.3 & 22.3 & 22.3 & 22.8 & 22.8 \\
22 & 35.9 & 36.5 & 35.8 & 36.6 & 36.7 \\
23 & 23.1 & 23.6 & 23.1 & 23.6 & 23.7 \\
24 & 125.8 & 126.4 & 125.7 & 125.3 & 126.5 \\
25 & 130.8 & 131.3 & 130.8 & 131.4 & 131.4 \\
26 & 25.7 & 26.2 & 25.6 & 26.2 & 26.2 \\
27 & 17.6 & 17.2 & 17.6 & 17.8 & 17.9 \\
28 & 27.9 & 28.5 & 27.9 & 27.2 & 28.8 \\
30 & 16.7 & 16.6 & 16.8 & 16.7 \\
30 & 17.8 & 17.1 & 17.8 & 17.6
\end{tabular}

3-Glucopyranosyl (inner)

$\begin{array}{llll}1^{\prime} & 105.0 & 105.4 & 106.7 \\ 2^{\prime} & 83.2 & 76.2 & 75.6 \\ 3^{\prime} & 78.1 & 79.3 & 77.8 \\ 4^{\prime} & 71.5 & 72.3 & 71.7 \\ 5^{\prime} & 78.1 & 79.1 & 78.2 \\ 6^{\prime} & 62.6 & 63.0 & 62.8\end{array}$

3-Glucopyranosyl (outer)

$\begin{array}{ll}1^{\prime \prime} & 105.9 \\ 2^{\prime \prime} & 77.0 \\ 3^{\prime \prime} & 79.1 \\ 4^{\prime \prime} & 71.5 \\ 5^{\prime \prime} & 78.1 \\ 6 " & 62.7\end{array}$

Fig. 7 Time course of hydrolysis of G-Rc by BG-1

20-Glucopyranosyl

\begin{tabular}{llllll}
$1^{\prime}$ & 98.1 & 98.5 & 98.1 & 98.5 & 98.7 \\
$2^{\prime}$ & 75.0 & 75.2 & 75.0 & 75.4 & 75.6 \\
\hline
\end{tabular}


Table 3 continued

\begin{tabular}{lccccc}
\hline Carbon no & G-Rd & C-Mc1 & G-F2 & C-Mc & C-K \\
\hline $3^{\prime}$ & 77.8 & 78.6 & 79.0 & 79.7 & 77.8 \\
$4^{\prime}$ & 71.4 & 72.1 & 71.3 & 72.6 & 72.1 \\
$5^{\prime}$ & 78.0 & 76.9 & 78.5 & 77.0 & 78.5 \\
$6^{\prime}$ & 62.5 & 68.8 & 62.5 & 68.9 & 63.4 \\
20-Arabinofuranosyl & & & & \\
$1^{\prime \prime}$ & & 110.5 & & 110.5 & \\
$2^{\prime \prime}$ & & 83.7 & & 83.7 & \\
$3^{\prime \prime}$ & & 78.7 & & 78.6 & \\
$4^{\prime \prime}$ & & 86.5 & & 86.5 & \\
$5^{\prime \prime}$ & & 63.0 & & 83.1 & \\
\hline
\end{tabular}

C-3 position of the G-Rc aglycone to produce $\mathrm{C}-\mathrm{Mc} 1$, followed by hydrolysis of the inner glucosidic linkage attached to the $\mathrm{C}-3$ position to produce $\mathrm{C}-\mathrm{Mc}$.

\section{Discussion}

In the screening for mushroom mycelia containing G-Rchydrolyzing activity, we found that enzyme preparation from A. mellea mycelia could efficiently convert G-Rc to $\mathrm{C}-\mathrm{Mc}$ and $\mathrm{C}-\mathrm{K}$, whereas enzyme preparations from G. lucidum, P. baumii, G. applanata, and P. ostreatus produced of G-Rd as a final product. Armillaria mellea $\beta$-glucosidase exists in three isomeric forms (BG-1, BG-2 and BG-3) that they exhibited different retention behaviors on DEAE cellulose column and hydrolytic activity toward $p$ NP- $\beta$-D-glucopyranoside. Moreover, when G-Rc, G-Rb1 and G-Rd were used as the substrates, BG-1 showed different hydrolytic activity from those of BG-2 and BG-3. These results demonstrate that $\beta$-glucosidases from G. lucidum, P. baumii, E. applanata and P. ostreatus mycelia selectively hydrolyzed $\alpha-(1 \rightarrow 6)$-arabinofuranosidic linkage at the $\mathrm{C}-20$ position of G-Rc without attacking any other $\beta$-glucosidic and arabinofuranosidic linkages. These results were also similar to those for ginsenoside Rb1-hydrolyzing $\beta$-D-glucosidases purified from Achatina fulica (Luan et al. 2006), Cladosporiun fulvum (Zhao et al. 2009), and ginsenoside $\alpha$-arabinofuranosidase isolated from fresh ginseng root (Zhang et al. 2002). G-Rb1-hydrolyzing $\beta$-glucosidases from $A$. fulica and C. fulvum have highly selective hydrolytic activities toward the $\beta$ - $(1 \rightarrow 6)$-glucosidic linkage attached to the $\mathrm{C}-20$ position of PPD-type ginsenosides without any activity toward other glucosidic linkages.

The fruiting body of A. mellea, known as honey mushroom, has been used as a health food in various forms and for dietary supplementation (Chen et al. 2015). In traditional Chinese medicine, the fruiting body and mycelia of $A$. mellea have been used for treating a variety of complaints including palsy, headache, hypertension, insomnia, vertigo, neurasthenia, and for neuroprotection (Lung and Chang 2011; Chen et al. 2015). As Fig. 8a shows, the hydrolysis of G-Rc by BG-1 was significantly influenced by the reaction temperature. BG-1 exhibited potent G-Rc hydrolyzing activity from 40 to $60{ }^{\circ} \mathrm{C}$; the optimum temperature for $\mathrm{C}-\mathrm{Mc}$ formation was between 55 and $60{ }^{\circ} \mathrm{C}$ while that for $\mathrm{C}-\mathrm{K}$ formation from G-Rc was between 45 and $50{ }^{\circ} \mathrm{C}$. Generally, the optimum temperatures for ginsenoside hydrolyzing enzymes from human intestinal bacteria and soil microorganisms are in the range $37-45^{\circ} \mathrm{C}$ (Park et al. 2010; Wang et al. 2011; Yang et al. 2015). The optimum temperature range of BG-1 in this study was slightly higher than those in previous studies that reported the optimum temperatures of the ginsenoside hydrolyzing enzymes from microorganisms such as Aspergillus sp., Penicillium sp., Trichoderma sp., Absidia sp., and Bifidobacterium sp. which were all in the range of $37-50{ }^{\circ} \mathrm{C}$ (Park et al. 2010; Yang et al. $2015)$. The $\beta$-glucosidases prepared from the cultured mycelia of white rot fungi such as Lentinus edodes, Grifola fondrosa, Polyporus squamosus, and Trametes versicolor exhibited temperature optima between 60 and $70{ }^{\circ} \mathrm{C}$ (Mfombep et al. 2013). The optimum $\mathrm{pH}$ for $\mathrm{C}-\mathrm{Mc}$ and $\mathrm{C}-\mathrm{K}$ formation from $\mathrm{G}-\mathrm{Rc}$ by $\mathrm{BG}-1$
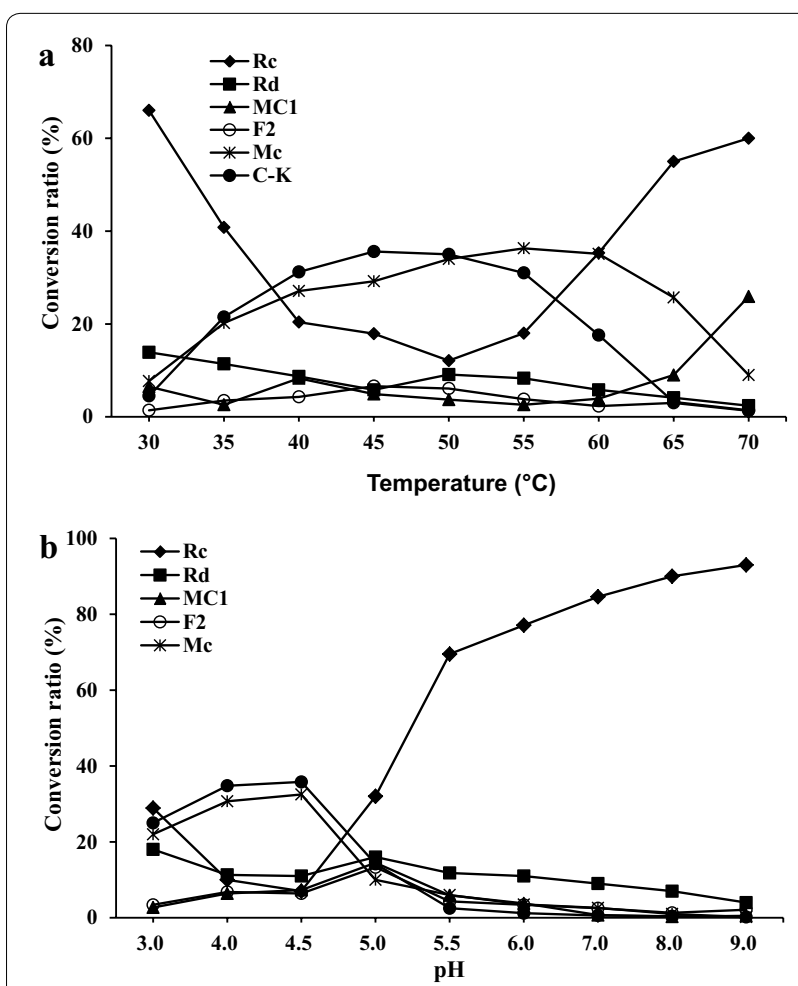

Fig. 8 a Influence of temperature on hydrolysis of G-Rc by BG-1. b Influence of $\mathrm{pH}$ on hydrolysis of G-Rc by BG-1 


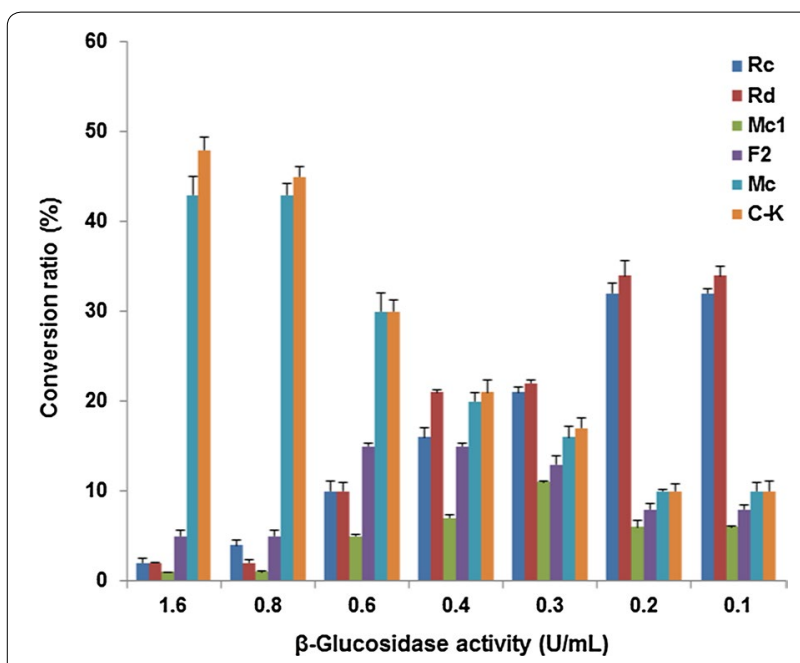

Fig. 9 Influence of enzyme concentration on hydrolysis of G-Rc by BG-1

was between 4.0 and 4.5 and the hydrolytic activity of G-Rc was decreased above pH 5.0. A previous study (Mfombep et al. 2013) reported that the optimum $\mathrm{pH}$ range for $\beta$-glucosidase activities from the cultured mycelia of white rot fungi was between 3.8 and 5.0. Our result showed that weakly acidic conditions are ideal for the formation of C-Mc and C-K from G-Rc by BG-1. The effect of $\mathrm{pH}$ on microbial and enzymatic hydrolysis of PPD-type ginsenosides has been extensively studied with microbial enzymes isolated from various sources. These enzymes for the transformation of PPD-type ginsenosides including G-Rc showed optimal activity in the range $\mathrm{pH}$ 4.0-6.0 (Park et al. 2010; Yang et al. 2015). In this study, the conversion ratio of G-Rc into $\mathrm{C}-\mathrm{K}$ and $\mathrm{C}-\mathrm{Mc}$ was greatly influenced by the enzyme concentration. When $2.0 \mathrm{mg}$ of G-Rc was incubated with reaction mixture $(1 \mathrm{ml})$ containing $1.6 \mathrm{U}$ of $\beta$-glucosidase activity for $96 \mathrm{~h}$ at $45^{\circ} \mathrm{C}$, G-Rc was mostly hydrolyzed to $\mathrm{C}-\mathrm{Mc}$ and $\mathrm{C}-\mathrm{K}$, with a conversion yield of 43 and $48 \%$, respectively. Several $\beta$-glycosidases with the ability to transform major PPD-type ginsenosides into $\mathrm{C}-\mathrm{K}$ have been reported. The biotransformation ratios from G-Rb1, G-Rb2 or G-Rc into C-K as the sole metabolite by microbial $\beta$-glucosidases from Paecilomyces bainier, Pyrococcus furiosus or Terrabacter ginsenosidimutans were between 77 and 94\% (Yang et al. 2015). However, unusually, $\beta$-glucosidase from Sulfolobus acidocaldarius produced C-Mc from G-Rc, with a conversion yield of $100 \%(\mathrm{~mol} / \mathrm{mol})$ (Noh and Oh 2009).

In conclusion, $\mathrm{BG}-1$, one of $\beta$-glucosidases purified from A. mellea mycelia, exhibited potent hydrolytic activity toward G-Rc. The optimum conditions for $\mathrm{C}-\mathrm{Mc}$ and $\mathrm{C}-\mathrm{K}$ formation from G-Rc were reaction time of $72-96 \mathrm{~h}$ and $\mathrm{pH}$ 4.0-4.5. The optimum temperature for $\mathrm{C}-\mathrm{K}$ formation from $\mathrm{G}-\mathrm{Rc}$ was $45-50{ }^{\circ} \mathrm{C}$, while that for $\mathrm{C}-\mathrm{Mc}$ formation was between 55 and $60{ }^{\circ} \mathrm{C}$. The pathways for formation of C-Mc and $\mathrm{C}-\mathrm{K}$ form G-Rc were G-Rc $\rightarrow \mathrm{C}-\mathrm{Mc} 1 \rightarrow \mathrm{C}-\mathrm{Mc}$ and G-Rc $\rightarrow$ G-Rd $\rightarrow$ G-F2 $\rightarrow$ C-K, respectively. C-Mc was also slowly hydrolyzed $\alpha-(1 \rightarrow 6)$-arabinofuranosidic linkage at the $\mathrm{C}-20$ site to produce $\mathrm{C}-\mathrm{K}$ with reaction time prolongation $(\geq 96 \mathrm{~h})$. These results suggest that $\beta$-glucosidase (BG-1) purified from A. mellea mycelia can be used to efficiently produce more pharmacologically

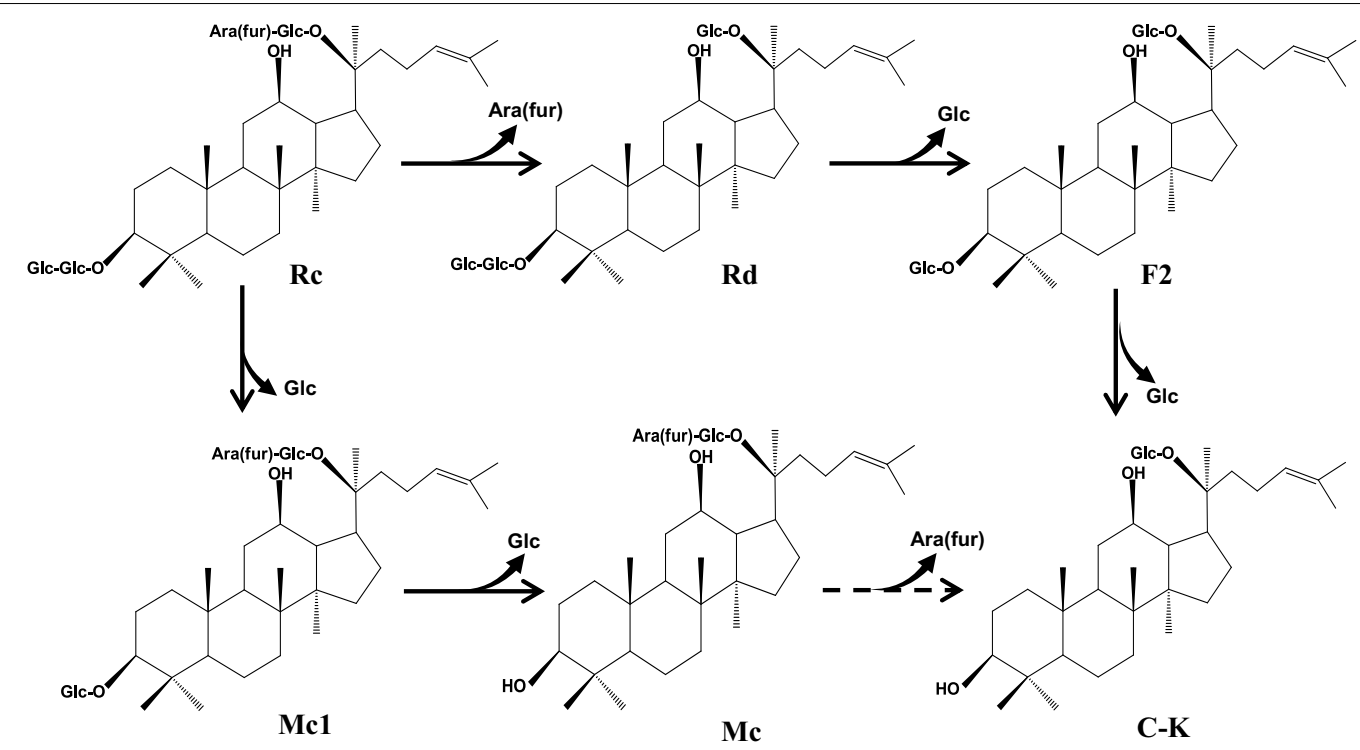

Fig. 10 Pathways of C-Mc and C-K formation from G-Rc by BG-1 


\section{active ginsenosides, $\mathrm{C}-\mathrm{Mc}$ and $\mathrm{C}-\mathrm{K}$ from $\mathrm{G}-\mathrm{Rc}$ under controlled reaction conditions.}

\begin{abstract}
Abbreviations
AMMEP: ammonium sulfate (30-80\%) precipitate isolated from Armillaria mellea mycelia; HPLC: high performance liquid chromatography; UPLC/Q-TOFMS: ultra performance liquid chromatography/quardruple-time of flight mass spectrometry; NMR: nuclear magnetic resonance; BSA: bovine serum albumin; DEAE: diethylaminoethyl; MUG: 4-methylumbelliferyl- $\beta$-D-glucopyranoside; SDS-PAGE: sodium dodecyl sulfate-polyacrylamide gel electrophoresis; TLC: thin layer chromatography; PPD: protopanaxadiol; PPT: protopanaxatriol; pNP: p-nitrophenyl; KACC: Korean Agricultural Culture Collection; ESI: electrospray ionization; UV: ultraviolet.
\end{abstract}

\section{Authors' contributions}

Designing of study: MKK, mushroom cultivation and enzyme isolation: MSY, NSR, isolation and identification of hydrolysis products: YHK, HPLC analysis: MJK, enzyme characterization: JU, YES, manuscript drafting; JU, YHK. All authors read and approved the final manuscript.

\section{Author details}

1 Department of Food Science and Technology, Chonbuk National University, Jeonju 54896, Republic of Korea. ${ }^{2}$ Department of Food Science and Biotechnology, Chonbuk National University, Iksan 54596, Republic of Korea. ${ }^{3}$ Agricultural Research and Extension Services, Iksan 54591, Republic of Korea.

\section{Acknowledgements}

We thank Dr. Hee-Won Park for his help in UPLC-Q-TOF-MS analysis, Korea Ginseng Corporation Research Institute, Daejeon, Republic of Korea.

\section{Competing interests}

The authors declare that they have no competing interests.

\section{Ethical approval}

This article does not contain any studies concerned with experimentation on human or animals.

\section{Funding}

This work was supported by Korea Institute of Planning, and Evaluation for Technology in Food, Agriculture, Forestry and Fisheries (IPET) through (Agri-Bioindustry Technology Development Program), funded by Ministry of Agriculture, Food and Rural Affairs (MAFRA) (code: 3140879-02-1-SB030).

Received: 19 October 2016 Accepted: 27 October 2016

Published online: 11 November 2016

\section{References}

Attele AS, Wu JA, Yuan CS (1999) Ginseng pharmacology: multiple constituents and multiple actions. Biochem Pharmacol 58(11):1685-1693. doi:10.1016/S0006-2952(99)00212-9

Bae EA, Choo MK, Park EK, Park SY, Shin HY, Kim DH (2002) Metabolism of ginsenoside Rc by human intestinal bacteria and its related antiallergic activity. Biol Pharm Bull 25(6):743-747. doi:10.1248/bpb.25.743

Baldrian P, Valášková V (2008) Degradation of cellulose by basidiomycetous fungi. FEMS Microbiol Rev 32:501-521. doi:10.1111/j.1574-6976.2008.00106.x

Buswell JA, Cai YJ, Chang ST, Peberdy JF, Fu SY, Yu HS (1996) Lignocellulolytic enzyme profiles of edible mushroom fungi. World I Microbiol Biotechnol 12:537-542. doi:10.1007/BF00419469

Chen YJ, Nose M, Ogihara Y (1987) Alkaline cleavage of ginsenosides. Chem Pharm Bull 35(4):1653-1655. doi:10.1248/cpb.35.1653

Chen CC, Kuo YH, Cheng JJ, Sung PJ, Ni CL, Chen CC, Shen CC (2015) Three new sesquiterpene aryl esters from the mycelium of Armillaria mellea. Molecules 20(6):9994-10003. doi:10.3390/molecules20069994

Chi H, Ji GE (2005) Transformation of ginsenosides Rb1 and Re from Panax ginseng by food microorganisms. Biotechnol Lett 27(11):765-771. doi:10.1007/s10529-005-5632-y
Christensen LP (2008) Ginsenosides: chemistry, biosynthesis, analysis, and potential health effects, chap 1. In: Taylor SL (ed) Advances in food and nutrition research, vol 55. Elsevier, Amsterdam, pp 1-99. doi:10.1016/ S1043-4526(08)00401-4

Han BH, Park MH, Han YN, Woo LK, Sankawa U, Yahara S, Tanaka O (1982) Degradation of ginseng saponins under mild acidic conditions. Planta Med 44(3):146-149. doi:10.1055/s-2007-971425

Hasegawa H, Sung JH, Matsumiya S, Uchiyama M (1996) Main ginseng metabolites formed by intestinal bacteria. Planta Med 62(5):453-457. doi: 10.1055/s-2006-957938

Hasegawa H, Sung JH, Benno Y (1997) Role of human intestinal Prevotella oris in hydrolyzing ginseng saponins. Planta Med 63(5):436-440. doi:10.105 5/s-2006-957729

Karikura M, Miyase T, Tanizawa H, Taniyama T, Takino Y (1991) Studies on absorption, distribution, excretion and metabolism of ginseng saponin. VII. Comparison of the decomposition modes of ginsenoside-Rb1 and -Rb2 in the digestive tract of rats. Chem Pharm Bull 39(9):2357-2361. doi:10.1248/cpb.39.2357

Laemmli UK (1970) Cleavage of structural proteins during the assembly of the head of bacteriophage T4. Nature 227:680-685. doi:10.1038/227680a0

Lee DC, Lau AS (2011) Effects of Panax ginseng on tumor necrosis factor-amediated inflammation: a mini-review. Molecules 16(4):2802-2816. doi:10.3390/molecules 16042802

Lee BH, Lee SJ, Hui JH, Lee S, Sung JH, Huh JD, Moon CK (1998) In vitro antigenotoxic activity of novel ginseng saponin metabolites formed by intestinal bacteria. Planta Med 64(6):500-503. doi:10.1055/s-2006-957501

Li W, Zhang M, Gu J, Meng ZJ, Zhao LC, Zheng YN, Chen L, Yang GL (2012) Hypoglycemic effect of protopanaxadiol-type ginsenosides and compound $\mathrm{K}$ on type 2 diabetes mice induced by high-fat diet combining with streptozotocin via suppression of hepatic gluconeogenesis. Fitoterapia 83(1):192-198. doi:10.1016/j.fitote.2011.10.011

Liu KK, Wang QT, Yang SM, Chen JY, Wu HX, Wei W (2014) Ginsenoside compound $\mathrm{K}$ suppresses the abnormal activation of $\mathrm{T}$ lymphocytes in mice with collagen-induced arthritis. Acta Pharmacol Sin 35(5):599-612. doi:10.1038/aps.2014.7

Liu CY, Zhou RX, Sun CK, Jin YH, Yu HS, Zhang TY, Xu LQ, Jin FX (2015) Preparation of minor ginsenosides $C-M C, C-Y, F 2$, and C-K from American ginseng PPD-ginsenoside using special ginsenosidase type-1 from Aspergillus niger g848. J Ginseng Res 39(3):221-229. doi:10.1016/j.jgr.2014.12.003

Luan H, Liu X, Qi X, Hu Y, Hao D, Cui Y, Yang L (2006) Purificatioin and characterization of a novel stable ginsenoside Rb1-hydrolyzing $\beta$-D-glucosidase from China white jade snail. Process Biochem 41(9):1974-1980. doi:10.1016/j.procbio.2006.04.011

Lung MY, Chang YC (2011) Antioxidant properties of the edible basidiomycete Armillaria mellea in submerged cultures. Int J Mol Sci 12(10):6367-6384. doi:10.3390/ijms12106367

Mfombep PM, Senwo ZN, Isikhuemhen OS (2013) Enzymatic activities and kinetic properties of $\beta$-glucosidase from selected white rot fungi. Adv Biol Chem 3(2):198-207. doi:10.4236/abc.2013.32025

Noh KH, Oh DK (2009) Production of the rare ginsenosides compound K, compound $Y$, and compound Mc by a thermostable $\beta$-glycosidase from Sulfolobus acidocaldarius. Biol Pharm Bull 32(11):1830-1835. doi:10.1248/ bpb.32.1830

Park JD, Rhee DK, Lee YH (2005) Biological activities and chemistry of saponins from Panax ginseng C. A. Meyer. Phytochem Rev 4(2):159-175. doi:10.1007/s11101-005-2835-8

Park CS, Yoo MH, Noh KH, Oh DK (2010) Biotransformation of ginsenosides by hydrolyzing the sugar moieties of ginsenosides using microbial glycosidases. Appl Microbiol Biotechnol 87(1):9-19. doi:10.1007/ s00253-010-2567-6

Park JS, Shin JA, Jung JS, Hyun JW, Van Le TK, Kim DH, Park EM, Kim HS (2012) Anti-inflammatory mechanism of compound $\mathrm{K}$ in activated microglia and its neuroprotective effect on experimental stroke in mice. J Pharmacol Exp Ther 341(1):59-67. doi:10.1124/jpet.111.189035

Park HW, In G, Han ST, Lee MW, Kim SY, Kim KT, Cho BG, Han GH, Chang IM (2013) Simultaneous determination of 30 ginsenosides in Panax ginseng preparations using ultra performance liquid chromatography. J Ginseng Res 37(4):457-467. doi:10.5142/jgr.2013.37.457

Sanada S, Kondo N, Shoji J, Tanaka O, Shibata S (1974) Studies on the saponins of ginseng. Structures of ginsenoside-Ro, -Rb1, -Rb2, -Rc, and -Rd. Chem Pharm Bull 22(2):421-428. doi:10.1248/cpb.22.421 
Tawab MA, Bahr U, Karas M, Wurglics M, Schubert-Zsilavecz M (2003) Degradation of ginsenosides in humans after oral administration. Drug Metab Dispos 31(8):1065-1071. doi:10.1124/dmd.31.8.1065

Upadhyaya J, Kim MJ, Kim YH, Ko SR, Park HW, Kim MK (2016) Enzymatic formation of compound-K from ginsenoside $\mathrm{R} b_{1}$ by enzymatic preparation from cultured mycelia of Armillaria mellea. J Ginseng Res 40(2):105-112. doi:10.1016/j.jgr.2015.05.007

Wandrey C, Liese A, Kihumbu D (2000) Industrial biocatalysis: past, present, and future. Org Proc Res Dev 4:286-290. doi:10.1021/op990101।

Wang L, Liu QM, Sung BH, An DS, Lee HG, Kim SG, Kim SC, Lee ST, Im WT (2011) Bioconversion of ginsenosides $\mathrm{Rb}_{1}, \mathrm{Rb}, \mathrm{Rc}$ and $\mathrm{Rd}$ by novel $\beta$-glucosidase hydrolyzing outer 3-O glycoside from Sphingomonas sp. 2F2: cloning, expression, and enzyme characterization. J Biotechnol 156(2):125-133. doi:10.1016/j.jbiotec.2011.07.024
Yang XD, Yang YY, Ouyang DS, Yang GP (2015) A review of biotransformation and pharmacology of ginsenoside compound K. Fitoterapia 100:208-220. doi:10.1016/j.fitote.2014.11.019

Zhang C, Yu H, Bao Y, An L, Jin F (2002) Purification and characterization of ginsenoside-a-arabinofuranase hydrolyzing ginsenoside $R c$ to $R d$ from fresh root of Panax ginseng. Process Biochem 37(7):793-798. doi:10.1016/ S0032-9592(01)00275-8

Zhao X, Gao L, Wang J, Bi H, Gao J, Du X, Zhou Y, Tai G (2009) A novel ginsenoside Rb1-hydrolyzing $\beta$-D-glucosidase from Cladosporium fulvum. Process Biochem 44(6):612-618. doi:10.1016/j.procbio.2009.01.016 